\title{
Comparison of histomorphology and DNA preservation produced by fixatives in the veterinary diagnostic laboratory setting
}

Histopathology is the most useful tool for diagnosis of a number of diseases, especially cancer. To be effective, histopathology requires that tissues be fixed prior to processing. Formalin is currently the most common histologic fixative, offering many advantages: it is cheap, readily available, and pathologists are routinely trained to examine tissues fixed in formalin. However, formalin fixation substantially degrades tissue DNA, hindering subsequent use in diagnostics and research. We therefore evaluated three alternative fixatives, TissueTek ${ }^{\circledR}$ Xpress ${ }^{\circledR}$ Molecular Fixative, modified methacarn, and PAXgene®, all of which have been proposed as formalin alternatives, to determine their suitability for routine use in a veterinary diagnostic laboratory. This was accomplished by examining the histomorphology of sections produced from fixed tissues as well as the ability to amplify fragments from extracted DNA. Tissues were sampled from two dogs and four cats, fixed for 24-48 hours, and processed routinely. While all fixatives produced acceptable histomorphology, formalin had significantly better morphologic characteristics than the other three fixatives. Alternative fixatives generally had better DNA amplification than formalin, although results varied somewhat depending on the tissue examined. While no fixative is yet ready to replace formalin, the alternative fixatives examined may be useful as adjuncts to formalin in diagnostic practices. 


\section{Comparison of histomorphology and DNA preservation produced by fixatives in the \\ 2 veterinary diagnostic laboratory setting}

3 Abstract: Histopathology is the most useful tool for diagnosis of a number of diseases, especially

4 cancer. To be effective, histopathology requires that tissues be fixed prior to processing. Formalin

5 is currently the most common histologic fixative, offering many advantages: it is cheap, readily

6 available, and pathologists are routinely trained to examine tissues fixed in formalin. However,

7 formalin fixation substantially degrades tissue DNA, hindering subsequent use in diagnostics and

8 research. We therefore evaluated three alternative fixatives, TissueTek ${ }^{\circledR}$ Xpress ${ }^{\circledR}$ Molecular

9 Fixative, modified methacarn, and PAXgene ${ }^{\circledR}$, all of which have been proposed as formalin

10 alternatives, to determine their suitability for routine use in a veterinary diagnostic laboratory.

11 This was accomplished by examining the histomorphology of sections produced from

12 fixed tissues as well as the ability to amplify fragments from extracted DNA. Tissues were

13 sampled from two dogs and four cats, fixed for 24-48 hours, and processed routinely. While all

14 fixatives produced acceptable histomorphology, formalin had significantly better morphologic

15 characteristics than the other three fixatives. Alternative fixatives generally had better DNA

16 amplification than formalin, although results varied somewhat depending on the tissue examined.

17 While no fixative is yet ready to replace formalin, the alternative fixatives examined may be

18 useful as adjuncts to formalin in diagnostic practices. 
19 William F. Craft ${ }^{1}$, Julia A. Conway ${ }^{1}$, and Michael J. Dark ${ }^{1,2}$

201 - Department of Infectious Diseases and Pathology, College of Veterinary Medicine,

21 University of Florida, Gainesville, FL

$22-$ Emerging Pathogens Institute, University of Florida, Gainesville, FL

23 Corresponding Author:

$24 \quad$ Michael J. Dark

25 Department of Infectious Diseases and Pathology

26 College of Veterinary Medicine

27 P.O. Box 110880

28 Gainesville, FL 32611-0880

29 Phone: (352) 294-4138

30 E-mail: darkmich@ufl.edu 
Introduction:

32 Histopathology is the most useful tool for diagnosis of a number of diseases, especially

33 cancer. To be effective, histopathology requires that tissues be fixed prior to processing. The

34 ultimate tissue fixative for histopathology would create tissue histomorphology identical to

35 formalin, pose no hazard to human health, preserve nucleic material for an extended period of

36 time preferably at room temperatures, and be cost effective. Formalin has been the most common

37 histologic fixative for over 100 years (Fox et al. 1985) since it replaced alcohol fixation. Formalin

38 fixation offers many advantages: primarily, it is cheap and readily available. Pathologists are

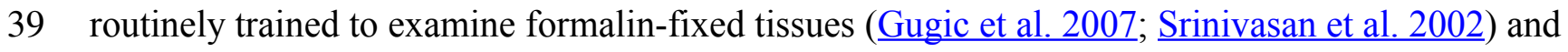

40 currently rarely see alcohol-fixed tissues. Many tissue qualities relied upon by pathologists to

41 make diagnoses, such as tinctorial qualities and texture, are dependent on fixation methods (Fox

42 et al. 1985).

43 However, formalin has several disadvantages as well. It can cause respiratory irritation

44 and is classified as a carcinogen (Bolt et al. 2010; Bosetti et al. 2008; Buesa 2008; Gugic et al.

45 2007). Formalin also degrades DNA, RNA, and proteins, which makes formalin-fixed tissues less

46 usable for downstream molecular diagnostics (Buesa 2008; Gugic et al. 2007). Formalin is an

47 aldehyde-based fixative that works by cross-linking proteins, which irreversibly damages proteins

48 and nucleic acids (Srinivasan et al. 2002). Typically, nucleic acids degrade in a time- and length-

49 dependent manner (Nam et al. 2014). Protein degradation is dependent on the protein selected, its

50 intracellular location, and the downstream application ( $\underline{\text { Kothmaier et al. 2011). }}$.

51 The most common method for preserving tissues for molecular diagnostics is freezing at

$52-80^{\circ} \mathrm{C}$, although this does not allow for histopathologic examination of tissues. This method itself 
53 has a number of issues, including requiring special equipment, difficulty in shipping samples to

54 laboratories, and requiring duplicate samples to be taken for histopathologic examination.

This is impractical for many private veterinary practices, as these generally lack the

56 facilities to freeze samples at $-80^{\circ} \mathrm{C}$ and many samples are too small to duplicate samples.

57 Therefore, alternative fixatives have been proposed to allow for both histopathologic examination

58 and molecular diagnostics (Cox et al. 2006; Gugic et al. 2007; Kap et al. 2011; Vincek et al.

59 2003). These have been shown to preserve nucleic acids with results similar to those obtained

60 with fresh or frozen tissues, while still preserving histomorphology. Some of the more successful

61 alternatives include Tissue-Tek ${ }^{\circledR}$ Xpress ${ }^{\circledR}$ Molecular Fixative (Gugic et al. 2007), PAXgene ${ }^{\circledR}$

62 (Kap et al. 2011), and modified methacarn solution (Cox et al. 2006). All of these are alcohol-

63 based and non-cross-linking. Evaluation of histomorphology preservation has varied among the

64 studies evaluating these fixatives and generally involve research settings using techniques that are

65 not practical in most clinical situations. In addition, some of these fixatives are currently cost

66 prohibitive in the veterinary clinical setting. The majority of the studies evaluating these fixatives

67 have evaluated single organs from humans or rodents (Cox et al. 2006) or multiple organs from

68 humans (Kap et al. 2011; Vincek et al. 2003). One study evaluated Tissue-Tek ${ }^{\circledR}$ Xpress ${ }^{\circledR}$

69 Molecular Fixative and formalin comparing histomorphology and RNA quality from a variety of

70 animal tissues (small animals, rodents, lagamorphs, birds, insects, and lizards) both at room

71 temperature and high ambient temperatures simulating field collection of samples (Gugic et al.

72 2007). They concluded that Tissue-Tek ${ }^{\circledR}$ Xpress ${ }^{\circledR}$ Molecular Fixative protected RNA and

73 provided acceptable histomorphology that would not hinder histologic diagnosis in the species

74 studied. Some studies evaluating multiple animal species have included limited numbers of

75 fixatives for comparison (Gugic et al. 2007; Vincek et al. 2003). 
The main limitation of all of these previous studies is that they have evaluated fixatives in

77 a research setting. There has not been a systematic evaluation of these to determine their utility in

78 the veterinary diagnostic setting. Alternative fixatives would have a number of benefits for

79 veterinary diagnostic laboratories, including (depending on the nature of the fixative) decreasing

80 hazardous waste disposal costs, decreasing health risks to laboratory workers, and enhancing the

81 power of retrospective studies Therefore, we conducted this study to determine how alternative

82 fixatives would function in a standard diagnostic laboratory setting by evaluating

83 histomorphology of a variety of tissues from dogs and cats, as well performing a quantitative

84 evaluation of recoverable DNA from tissues.

\section{Materials and Methods:}

All study protocols were approved by the University of Florida Institutional Animal Use

87 and Care Committee (approval \#201105654), and all animals were euthanized for reasons

88 unrelated to this project. Necropsies were performed on four cats that had finished another

89 research study and two shelter dogs within four hours of euthanasia. Replicate samples,

90 approximately $10 \times 10 \times 5 \mathrm{~mm}$, were collected from the liver, brain, lung, mesenteric lymph

91 nodes, kidney, and spleen. One sample of each tissue was frozen at $-80^{\circ} \mathrm{C}$. The remaining samples

92 were placed into 10\% neutral buffered formalin, Tissue-Tek ${ }^{\circledR}$ Xpress ${ }^{\circledR}$ Molecular Fixative (TT-

93 XMF), modified methacarn, and PAXgene ${ }^{\circledR}$, with a minimum of 1:10 tissue to fixative volume.

94 Samples were allowed to fix for 24-48 hours at room temperature with the exception of tissues in

95 PAXgene ${ }^{\circledR}$, which were fixed and preserved according to the manufacturer's protocol. In brief,

96 tissues were trimmed, placed into the supplied cassettes, immersed into chamber one for 4 hours,

97 and then switched into chamber two for 24-48 hours prior to processing. 
All tissues were processed with a Tissue-Tek processor using a standard overnight

99 protocol (excluding formalin steps) followed by paraffin embedding and hematoxylin and eosin

100 staining. The $10 \%$ neutral buffered formalin, Tissue-Tek ${ }^{\circledR}$ Xpress ${ }^{\circledR}$ Molecular Fixative, and

101 PAXgene ${ }^{\circledR}$ fixatives were purchased commercially (ThermoFisher Scientific, Waltham, MA).

102 Modified methacarn was prepared as previously described, using 8 parts methanol and 1 part

103 glacial acetic acid (Cox et al. 2006).

104

Histomorphology was evaluated by two blinded board-certified veterinary anatomic

105 pathologists (MJD, JAC) and one blinded anatomic pathology resident (WFC). Histomorphology

106 of nuclear, cytoplasmic, and cellular membrane detail were evaluated on a 1-4 scale (table 1).

107 Sample scores were averaged between all three evaluators. For one cat, the formalin-fixed lymph

108 node sample was lost from the block; therefore, formalin fixation histomorphometry scores for

109 lymph node are based on the remaining five samples. Both the individual components of the

110 histomorphometry score as well as the total score were evaluated using a Kruskal-Wallis test

111 (Lowry 2012) to determine if there was a difference between any of the four groups. If a

112 significant difference was found $(\mathrm{p}<0.05)$, the Mann-Whitney test was used to compare each

113 group to each other group, to determine significant differences between each individual fixative.

114 P-values were then adjusted using the Holm-Bonferroni correction for multiple comparisons,

115 using the p.adjust function of R v3.0.2. Fixatives were considered significantly different if the

116 Holm-Bonferroni corrected two-tailed Mann-Whitney $\mathrm{p}$ value was less than 0.05 . The minimum,

$11725^{\text {th }}$ quartile, median, $75^{\text {th }}$ quartile, and maximum were calculated for each tissue as well as for all

118 tissues combined using Microsoft Excel (v14.3.9, Microsoft Corp., Seattle, WA). Graphs were

119 generated using GNUplot (v.4.6, patchlevel 3).

Tissue scrolls were obtained from the paraffin blocks one week after processing and DNA

121 was extracted using the QIAamp DNA FFPE Tissue kit (Qiagen Inc., Valencia, CA). Primers 
122 were designed by aligning the sequences of the retinol-binding protein 3 , interstitial gene (IRBP)

123 from dog, mouse, rat, and human, and selecting regions that were relatively conserved, to

124 generate 100, 200, 300, 500, and 750 base pair long amplicons (table 2). Each reverse primer was

125 combined with the forward primer and combined with extracted DNA. These reactions were

126 amplified via PCR on an Applied Biosystems Veriti Thermal Cycler with the following

127 conditions: $96^{\circ} \mathrm{C}$ for 3 minutes, followed by 35 cycles of $96^{\circ} \mathrm{C}$ for 1 minute, $60^{\circ} \mathrm{C}$ for 1 minute,

128 then $72^{\circ} \mathrm{C}$ for 1 minute. This was followed by 7 minutes at $72^{\circ} \mathrm{C}$, with a final hold at $4^{\circ} \mathrm{C}$ until the

129 next morning. Samples were examined on a 1.25\% agarose gel via electrophoresis to ensure a

130 single band of the appropriate size was generated per lane. DNA extracted from tissues frozen at

$131-80^{\circ} \mathrm{C}$ using the QIAamp DNA Mini Kit (Qiagen Inc.) and water were used as positive and

132 negative controls, respectively..

133 The presence or absence of bands for all sizes was noted. The Kruskal-Wallis test was

134 used to determine if there was a significant difference between the maximum band size for any of

135 the fixatives. If significant $(\mathrm{p}<0.05)$, the Mann-Whitney test was used to compare each fixative

136 against each other to determine which differences were significant. P-values were adjusted using

137 the Holm-Bonferroni correction for multiple comparisons, using the p.adjust function of R

138 v3.0.2; significance was determined by a corrected two-tailed p-value $<0.05$. The minimum, $25^{\text {th }}$

139 quartile, median, $75^{\text {th }}$ quartile, and maximum calculated for each fixative and for each tissue

140 using Microsoft Excel. Graphs were generated using GNUplot (v.4.6, patchlevel 3).

141 Results:

\section{Histomorphology}

143 While the majority of the alternative fixatives produced adequate histomorphology in the 144 tissues examined, formalin fixed tissues consistently resulted in superior histomorphology. There 
145 was no statistically significant difference between mean histomorphology scores comparing dog 146 and cat tissues, and these were combined for subsequent analysis. The nuclear, cytoplasmic,

147 cellular membrane, and total scores averaged between all three examiners (figs. 1A-D) for

148 formalin fixed tissues were higher than for all other fixatives $(\mathrm{p}=0.0006)$, although there was

149 substantial variation with all fixatives (figs. 2A-D).

150 While a number of minor artifacts were noted, the primary difference noted between

151 formalin and the other fixatives was in erythrocytes. This is likely reflected in the significantly

152 higher scores for formalin vs. other fixatives in the spleen $(\mathrm{p}=0.0051)$, an organ made up in large 153 part by erythrocytes.

154 DNA Preservation

155 Formalin had significantly shorter total maximum DNA band sizes than modified 156 methacarn solution $(\mathrm{p}<0.0006)$ and PAXgene $(\mathrm{p}=0.0032)$ (fig. 3). In particular, the bands 157 obtained from lymph nodes were significantly smaller with formalin than with modified 158 methacarn ( $\mathrm{p}=0.0480)$ (fig. 4). Overall, modified methacarn solution performed as well or better 159 than the other fixatives for all tissues, with the best score in brain (median amplicon length of $160750 \mathrm{bp})$.

Discussion:

162 While alternative fixatives have been found to work well in research settings ( $\underline{\text { Cox et al. }}$ 163 2006; Kap et al. 2011; Vincek et al. 2003), these are not ready to replace formalin for routine 164 tissue processing in the veterinary diagnostic laboratory. All of the fixatives require tissues be 165 prevented from contacting formalin to benefit from their nucleic acid preserving qualities, which 166 would require laboratories to either maintain separate tissue processors or bar submission of 167 formalin-fixed tissues. Neither of these is practical in veterinary practice. Several fixatives 
168 produce excellent histomorphology with alternative processing techniques; this is also

169 impracticable in most veterinary diagnostic laboratories, as it would require separate processing

170 runs.

171 However, while no fixative is ideal from the standpoint of replacing formalin, all fixatives

172 produced interpretable slides. Therefore, using alternative fixatives may be useful in specific

173 circumstances where subsequent DNA isolation may be required. For example, tissue samples

174 from neoplasms may be saved separately to generate a tissue bank for subsequent research

175 projects. The specific alternative chosen should be based on the tissue selected, as well as

176 predicted needs for DNA amplification and preservation of histomorphology. For example, while

177 TT-XMF had better histomorphology scores in the kidney than either modified methacarn or

178 PAXgene, it had a lower median DNA amplicon size.

One characteristic observed with alternative fixatives was that bloody or congested tissues often had unfixed areas, which could result in missing lesions and inaccurate diagnoses. This has not been found in previous studies (Cox et al. 2006), and may be due to a number of factors. First, the size of sample taken will greatly influence fixation. For most veterinary diagnostic laboratories, $1 \mathrm{~cm}$ thick samples are considered standard for histopathologic examination. In many previous studies, samples taken for fixation were substantially thinner; for example, the study by Cox et al. used $15 \mathrm{~mm}$ x $8 \mathrm{~mm}$ x $3 \mathrm{~mm}$ samples. Other possibilities include differences in processing; microwave fixation ( $\underline{\text { Cox et al. 2006) }}$ ) or rapid tissue processing (Vincek et al. 2003) techniques have been used. Tuning the processing technique for the fixative selected would

188 likely improve fixation and the ultimate histomorphology. analysis would be required to determine whether these fixatives preserve RNA equally well.

191 Other variables require investigation to determine the best fixative for a particular application. 
192 These include the effects of fixation time on nucleic acid quality, as many samples will sit longer

193 than 24 hours before processing, as well as the effect of storage time after tissue processing but

194 before sectioning for nucleic acid isolation, since many blocks will be stored for a period of time

195 between the evaluation of histopathology and nucleic acid isolation. The latter is especially

196 important if laboratories set up tissue banks, as samples would be expected to be stored for 197 prolonged periods.

198 Conclusions:

199 While no fixative is ideal to replace formalin, alternative fixatives have generally

200 acceptable histomorphologic characteristics in most tissues and are valuable adjuncts to standard

201 formalin fixation. Investigators proposing to use an alternative fixative for a research project

202 should evaluate the project goals and requirements. Ideally, the fixative should be tested with

203 samples of the target organs to determine the best fixative, required processing techniques, and

204 histomorphology compromises before actual sample collection begins.

\section{Acknowledgements:}

206 The authors would like to acknowledge Patrick Knisley for his assistance with samples, the

207 University of Florida College of Veterinary Medicine Histopathology Laboratory for help with

208 tissue processing, and Antoinette McIntosh for help with DNA processing.

209 References:

210 Bolt HM, Degen GH, and Hengstler JG. 2010. The carcinogenicity debate on formaldehyde: How

211 to derive safe exposure limits? Archives of toxicology 84:421-422.

212 Bosetti C, McLaughlin JK, Tarone RE, Pira E, and La Vecchia C. 2008. Formaldehyde and

213 cancer risk: a quantitative review of cohort studies through 2006. Annals of oncology :

214 official journal of the European Society for Medical Oncology / ESMO 19:29-43. 
Buesa RJ. 2008. Histology without formalin? Annals of diagnostic pathology 12:387-396.

216 Cox ML, Schray CL, Luster CN, Stewart ZS, Korytko PJ, KN MK, Paulauskis JD, and Dunstan RW. 2006. Assessment of fixatives, fixation, and tissue processing on morphology and RNA integrity. Experimental and molecular pathology 80:183-191.

Fox $\mathrm{CH}$, Johnson FB, Whiting J, and Roller PP. 1985. Formaldehyde fixation. The journal of histochemistry and cytochemistry : official journal of the Histochemistry Society 33:845853.

222

Gugic D, Nassiri M, Nadji M, Morales A, and Vincek V. 2007. Novel tissue preservative and tissue fixative for comparative pathology and animal research. Journal of Experimental Animal Science 43:271-281.

Kap M, Smedts F, Oosterhuis W, Winther R, Christensen N, Reischauer B, Viertler C, Groelz D, Becker KF, Zatloukal K et al. . 2011. Histological assessment of PAXgene tissue fixation and stabilization reagents. PloS one 6:e27704.

Kothmaier H, Rohrer D, Stacher E, Quehenberger F, Becker KF, and Popper HH. 2011. Comparison of formalin-free tissue fixatives: a proteomic study testing their application for routine pathology and research. Archives of pathology \& laboratory medicine 135:744-752.

Lowry R. 2012. VassarStats: Website for Statistical Computation (accessed 3/1/2012 2012).

233 Nam SK, Im J, Kwak Y, Han N, Nam KH, Seo AN, and Lee HS. 2014. Effects of fixation and storage of human tissue samples on nucleic Acid preservation. Korean journal of pathology 48:36-42.

Srinivasan M, Sedmak D, and Jewell S. 2002. Effect of fixatives and tissue processing on the content and integrity of nucleic acids. The American journal of pathology 161:1961-1971.

238 Vincek V, Nassiri M, Nadji M, and Morales AR. 2003. A tissue fixative that protects macromolecules (DNA, RNA, and protein) and histomorphology in clinical samples. Laboratory investigation; a journal of technical methods and pathology 83:1427-1435. 


\section{Figure 1}

Comparison of histomorphology and DNA preservation produced by fixatives in the veterinary diagnostic laboratory setting Histomorphology scores for all animals and tissues combined.

Comparison of histomorphology and DNA preservation produced by fixatives in the veterinary diagnostic laboratory setting The median is represented by a red diamond, the box represents the $25^{\text {th }}$ and $75^{\text {th }}$ quartiles, and the whiskers represent $1.5 \times$ interquartile range.
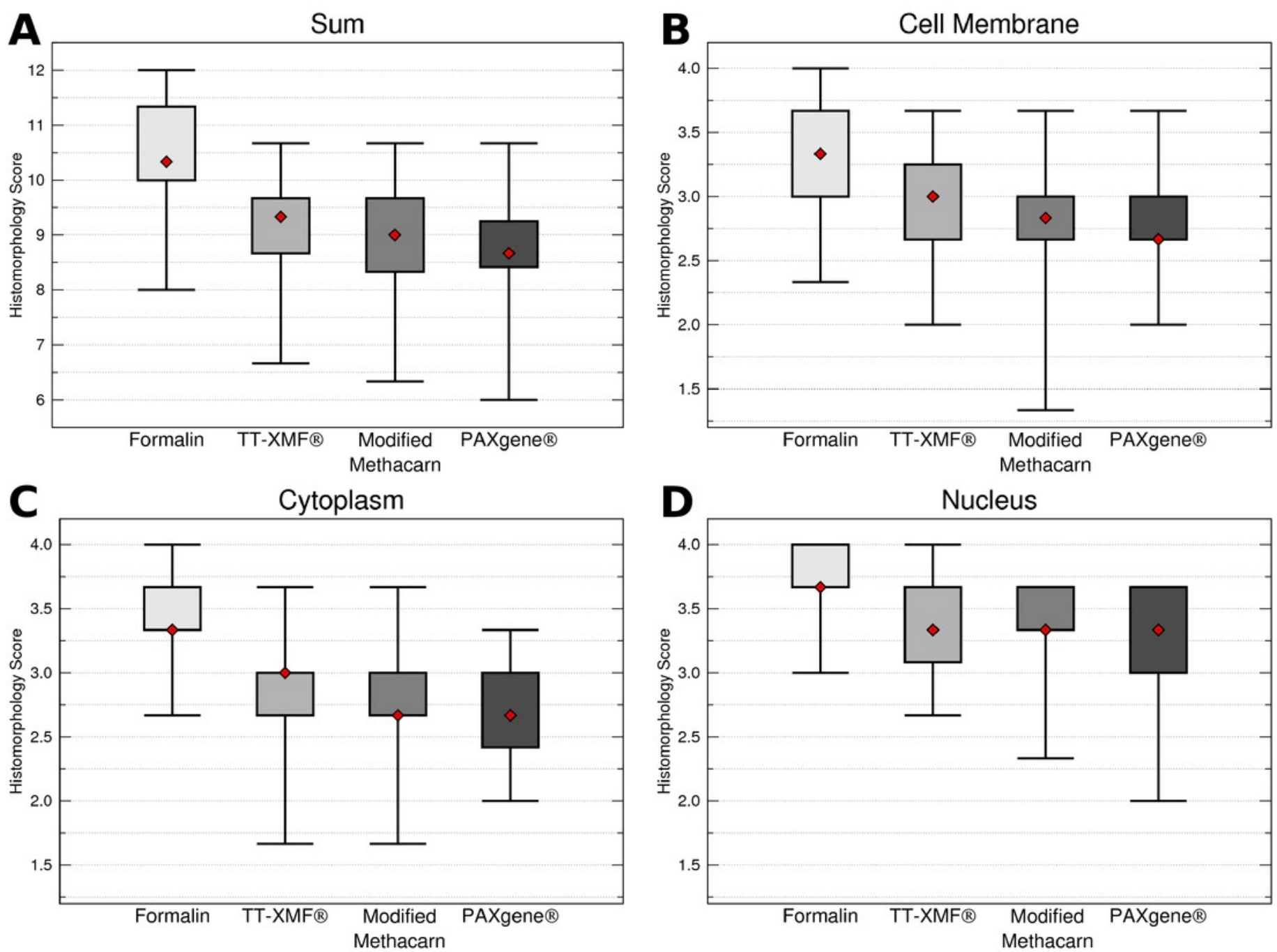


\section{Figure 2}

Comparison of histomorphology and DNA preservation produced by fixatives in the veterinary diagnostic laboratory setting Histomorphology scores for individual tissues.

Comparison of histomorphology and DNA preservation produced by fixatives in the veterinary diagnostic laboratory setting The median is represented by a red diamond, the box represents the $25^{\text {th }}$ and $75^{\text {th }}$ quartiles, and the whiskers represent $1.5 \times$ interquartile range.
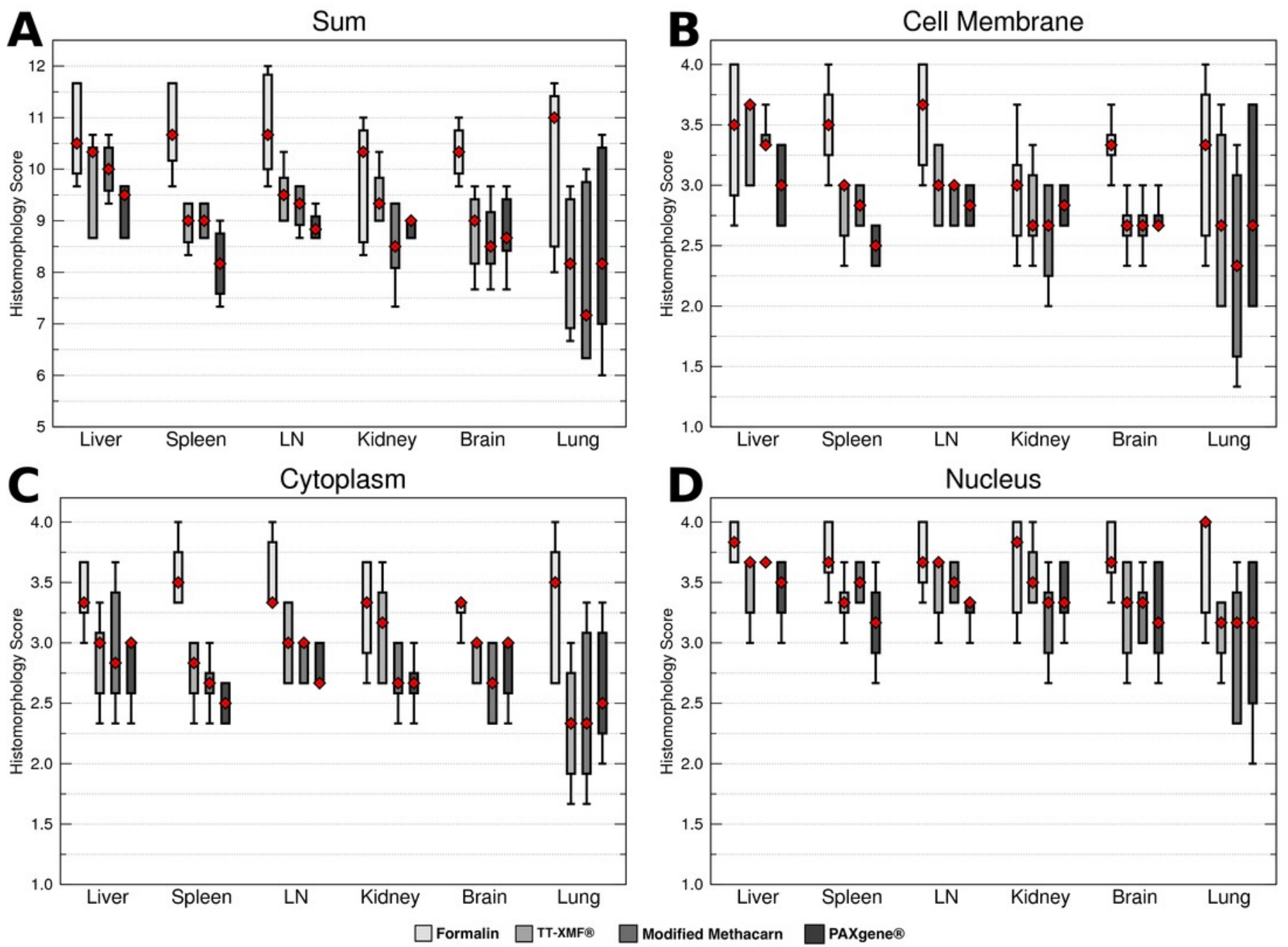


\section{Figure 3}

Maximum DNA amplicon size ranges for all samples combined.

The median is represented by a red diamond, the box represents the $25^{\text {th }}$ and $75^{\text {th }}$ quartiles, and the whiskers represent $1.5 \mathrm{x}$ interquartile range.

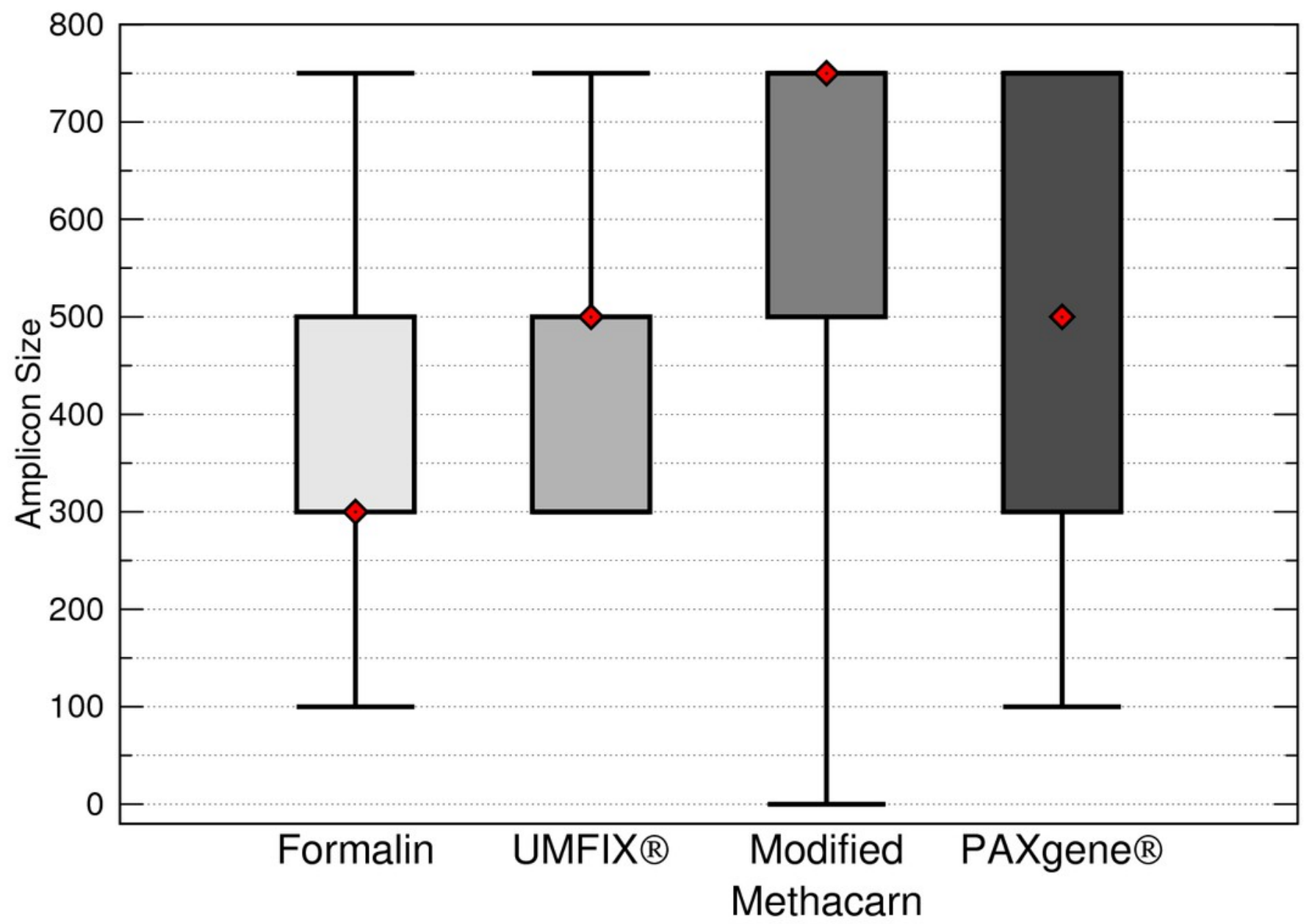




\section{Figure 4}

Maximum DNA amplicon size ranges for different tissue samples.

The median is represented by a red diamond, the box represents the $25^{\text {th }}$ and $75^{\text {th }}$ quartiles, and the whiskers represent $1.5 \mathrm{x}$ interquartile range.

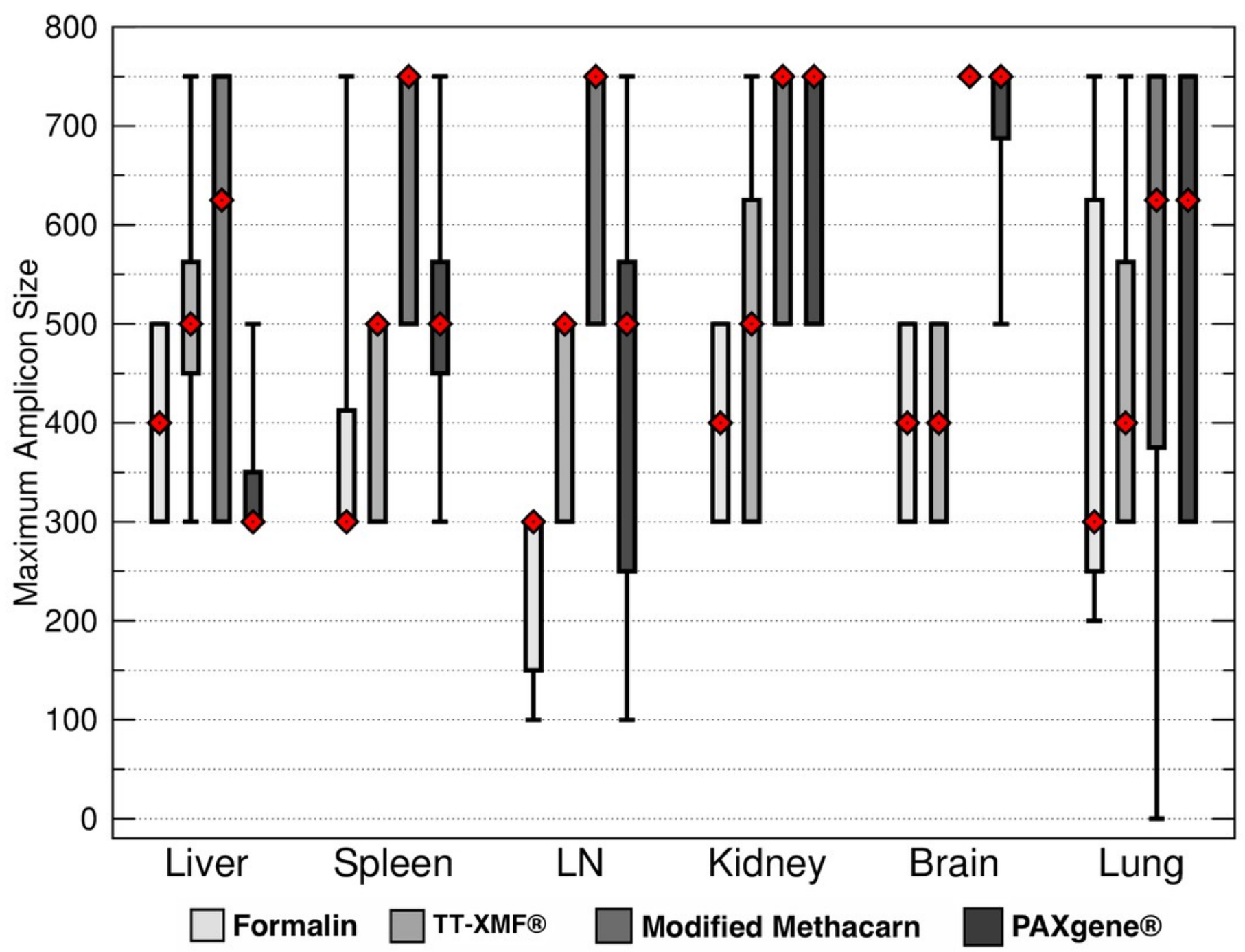




\section{Figure 5}

Representative fixative histomorphology - liver

Representative fixative histomorphology. Samples are from the liver of a single cat. A formalin, B - TT-XMF®, C - modified methacarn, D - PAXgene®.
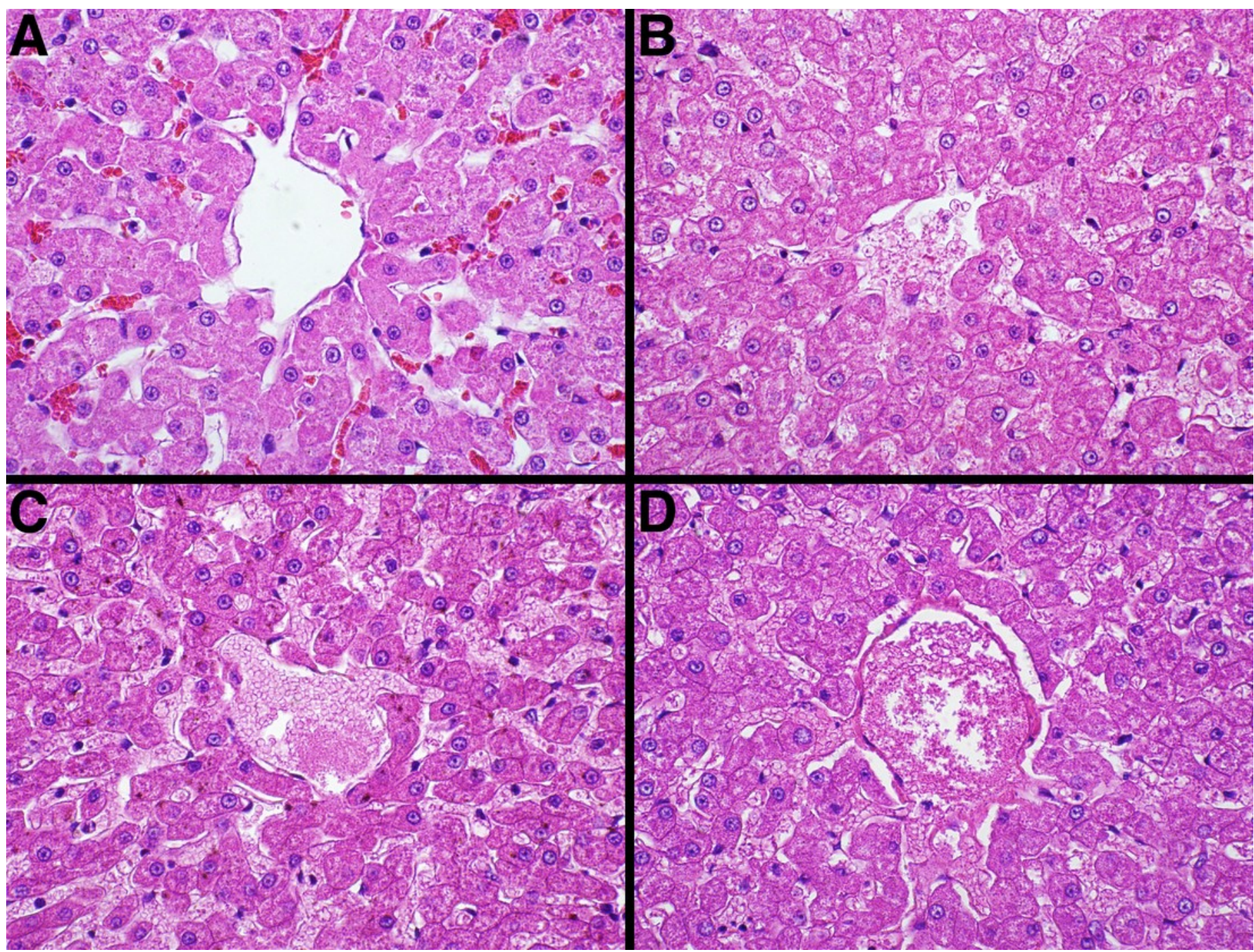


\section{Figure 6}

Representative fixative histomorphology - spleen

Samples are from the spleen of a single dog. A - formalin, B - TT-XMF®, C-modified methacarn, D - PAXgene®.

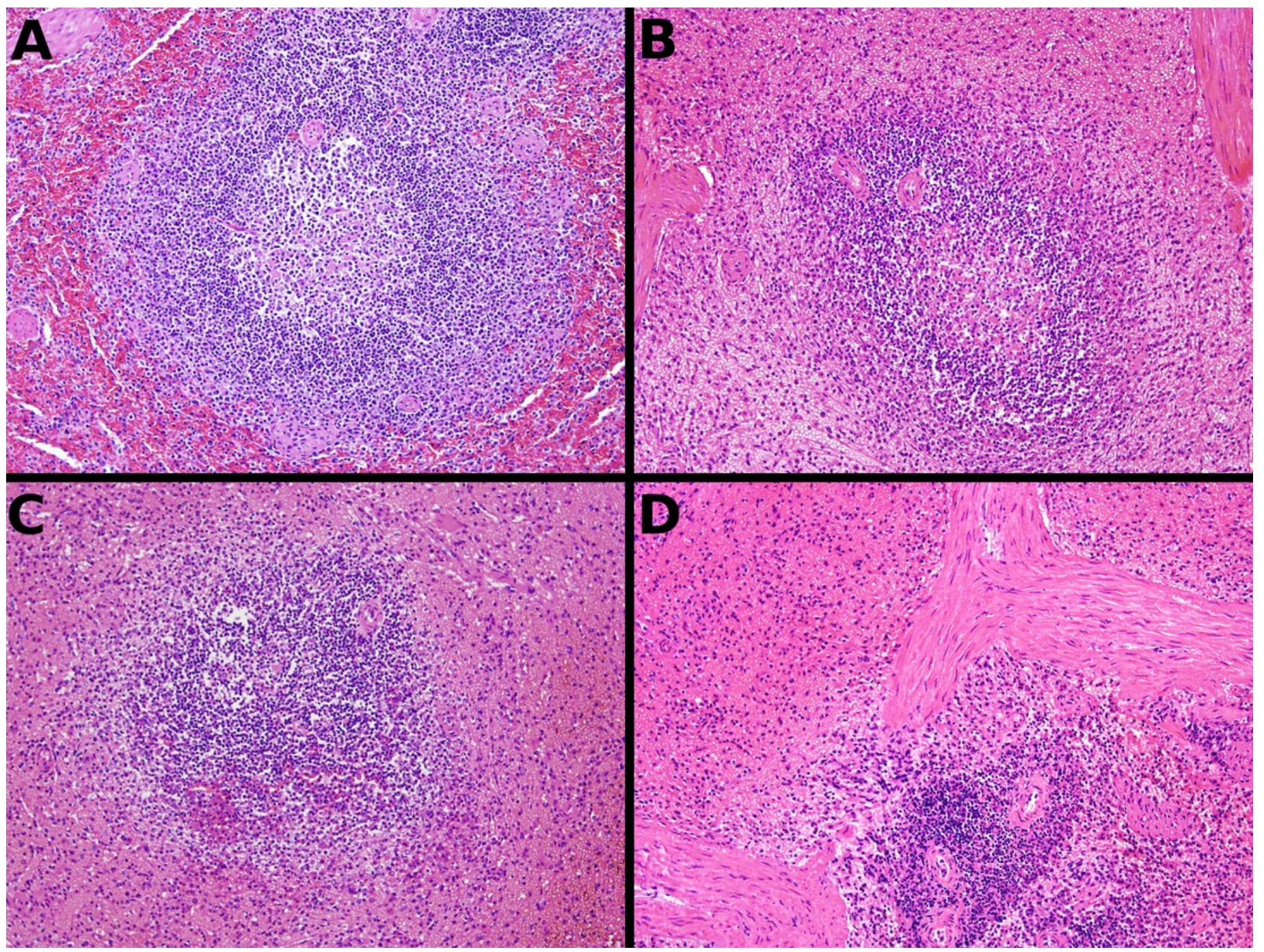




\section{Table 1 (on next page)}

Table 1

Histomorphology scoring criteria. 


\begin{tabular}{|c|c|c|}
\hline Characteristic & $\begin{array}{c}\text { Scor } \\
\mathrm{e}\end{array}$ & Criteria \\
\hline \multirow[t]{5}{*}{ Nuclear } & 4 & Sharp nuclear membrane;chromatin pattern clear;nucleolus, when present is distinct \\
\hline & $\frac{\circ}{3}$ & $\begin{array}{l}\text { Slight degradation in chromatin pattern, nucleolus when present, less distinct but discernable, sharp nuclear } \\
\text { membrane }\end{array}$ \\
\hline & 2 & Less distinct nuclear membrane;fuzzy chromatin pattern, nucleolus when present is difficult to discern \\
\hline & $\underline{\underline{1}}$ & Fuzzy nuclear membrane, chromatin pattern difficult to determine, nucleoli indetectable \\
\hline & 金 & Nucleus not able to be differentiated from cytoplasm \\
\hline \multirow[t]{5}{*}{ Cytoplasm } & $(4)$ & Normal cellular morphology easily determined \\
\hline & $\frac{3}{3}$ & Intracytoplasmic details fuzzy \\
\hline & दे & Only rare evidence of normal intracellular structures \\
\hline & 迹 & Increased cytoplasmic pallor, increased cytoplasmic eosinophilia \\
\hline & (1) & Cytoplasm homogenously pale eosinophilic with no evidence of organelles \\
\hline \multirow{6}{*}{$\begin{array}{l}\text { Cell } \\
\text { Membranes }\end{array}$} & 3 & \\
\hline & A & Cells have distinct intracellular;any normal substructures, if present, are easily distinguished \\
\hline & A & Loss of substructures (if present) in some cells; slight loss of intracellular details \\
\hline & 2 & Loss of substructures (if present) in most cells; obvious fuzzing of many cellular borders \\
\hline & 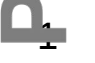 & No substructures detected; significant fuzzing of most cellular borders \\
\hline & 0 & Cells unable to be distinguished from adjacent cells \\
\hline
\end{tabular}




\section{Table 2 (on next page)}

Table 2

DNA primers used in this study. 


\begin{tabular}{ll} 
Primer Name & Sequence \\
\hline IRBP_F & $\begin{array}{l}\text { CCT KGT RCT GGA NAT } \\
\text { GGC }\end{array}$ \\
\hline IRBP_R1_100b & \\
$p$ & CTC TTG ATG GCC TGC TC \\
IRBP_R2_200b & GGC TCA TAG GAG ATG \\
$p$ & ACC AG \\
IRBP_R3_300b & CAG GTA GCC CAC RTT \\
$p$ & NCC CTC \\
IRBP_R4_400b & CGG AGR TCY AGC ACC \\
$p$ & AAG G \\
IRBP_R5_500b & GAT CTC WGT GGT NGT \\
$p$ & GTT GG \\
IRBP_R6_750b & CTC AGC TTC TGG AGG \\
$p$ & TCC \\
\hline
\end{tabular}

